\title{
Der 8er-Rat als Beteiligungsrevolution
}

Was könnte aus Deutschland werden, wenn wir wirklich alle Menschen beteiligen würden? - Vielleicht ein riesiges Chaos, vielleicht eine aktivere Demokratie, vielleicht auch schlicht nur ein neuer Dialog zwischen den Mächtigen und den Ohnmächtigen.

Als wir vor ein paar Jahren mit den ersten Gedanken zum 8er-Rat starteten, waren wir inspiriert von der Idee, alle Jugendlichen zu erreichen. Jetzt, nach den ersten Jahren der Praxis, sind wir zufrieden. Es ist anstrengend, es fordert alle Beteiligten heraus, aber es gelingt. Es macht Jugendliche aller sozialen Lagen und Bildungshintergründe stärker und trägt zu einem neuen Miteinander von Kommune, Schule und Jugendarbeit bei. Viele Bereiche, die sich lange gegenseitig als Konkurrenz verstanden haben, werden zu Kooperationspartnerinnen und Kooperationspartnern.

Der 8er-Rat ist für die Jugendbeteiligung eine Revolution, aber er fegt alte und andere Formen nicht vom Platz. Wir erleben, dass der 8er-Rat die Schülerinnen- und Schülervertretungsarbeit an der Schule stärker macht, weil junge Menschen wissen, dass sie sich erfolgreich einbringen können. Wir erleben, dass auch gewählte Jugendräte mit dem 8er-Rat kooperieren können und man gemeinsam mehr Erfolg hat. Aber vor allem erleben wir, dass Jugendliche sich einmischen und ihr Gemeinwesen verändern. In unseren Augen ist das alle Mühe wert. 